\title{
Experimentos com materiais alternativos aplicados ao ensino remoto de Química
}

\author{
Experiments with alternative materials applied to remote chemistry \\ teaching \\ Experimentos con materiales alternativos aplicados a la enseñanza remota de \\ la Química
}

\author{
Amanda Alves Barbosa (amada.barbosa@univasf.edu.br) \\ Universidade Federal do Vale do São Francisco - UNIVASF
}

\begin{abstract}
Resumo: Devido ao cenário de pandemia atribuído ao surgimento do novo Coronavírus e ao distanciamento social adotado para minimizar sua circulação e transmissão, o ensino remoto tornou-se uma realidade na área da educação. Trabalhar de forma remota gerou a necessidade de diversas adaptações no processo de ensino e aprendizagem, tornando-se ainda mais desafiador na área da Ciência, onde professores e alunos utilizam de atividades experimentais para desenvolver maior estímulo, interesse e aprendizado, caracterizando-se como um forte aliado nas metodologias de ensino. Diante do exposto, este artigo apresenta a descrição de experimentos da disciplina de Química Geral do curso de Licenciatura em Ciências da Natureza durante período de ensino remoto, os quais foram realizados pelos alunos do $2^{\circ}$ período a partir da adaptação de materiais e orientação do professor. Todos os experimentos foram construídos pelos estudantes em suas residências, além disso, os mesmos fizeram a gravação das etapas experimentais com as devidas explicações. Durante aula síncrona, os vídeos foram apresentados para a turma e as dificuldades e adaptações realizadas foram discutidas. Todos os alunos realizaram todos os experimentos e com base no aproveitamento destes, bem como, relatos dos estudantes a respeito da metodologia empregada, considera-se que o trabalho foi bastante exitoso.
\end{abstract}

Palavras-chave: Ensino remoto; Experimentos; Materiais alternativos; Química.

\begin{abstract}
Due to the pandemic scenario attributed to the emergence of the new Coronavirus and the social distance adopted to minimize its circulation and transmission, remote teaching has become a reality in the area of education. Working remotely generated the need for several adaptations in the teaching and learning process, making it even more challenging in the area of Science, where teachers and students use experimental activities to develop greater stimulus, interest and learning, being characterized as a strong ally in teaching methodologies. In view of the above, this article presents the description of experiments of the General Chemistry discipline of the Degree in Natural Sciences course during period of remote teaching, which were carried out by students of the 2 nd period from the adaptation of materials and teacher guidance. All experiments were built by students in their homes, in addition, they recorded the experimental steps with the necessary explanations. Based on the
\end{abstract}


students performance in the discipline, as well as the students reports about the methodology used, it is considered that the work was quite successful.

Keywords: Remote teaching; Experiments; Alternative materials; Chemistry.

Resumen: Debido al escenario pandémico atribuido a la aparición del nuevo Coronavirus y al distanciamiento social adoptado para minimizar su circulación y transmisión, la enseñanza remota se ha convertido en una realidad en el ámbito de la educación. El trabajo a distancia ha generado la necesidad de diversas adaptaciones en el proceso de enseñanza y aprendizaje, aún más desafiante en el área de la Ciencia, donde profesores y estudiantes utilizan actividades experimentales desarrollar un mayor estímulo, interés y aprendizaje, caracterizándose como un fuerte aliado en las metodologías de enseñanza. En vista de lo anterior, este artículo presenta la descripción de los experimentos de la disciplina de Química General de la Carrera en Ciencias de la Naturaleza durante un período de enseñanza remota, los cuales fueron realizados por los alumnos del $2^{\circ}$ periodo a partir de la adaptación de materiales y orientación del profesor. Todos los experimentos fueron construidos por los estudiantes en sus residencias, además, hicieron la grabación de los pasos experimentales con las explicaciones apropiadas. Durante las clases sincrónicas, los videos fueron presentados a la clase y se discutieron las dificultades y adaptaciones realizadas. Todos los estudiantes llevaron a cabo todos los experimentos y basados en el uso de estos, así como los informes de los estudiantes sobre la metodología empleada, el trabajo se considera bastante exitoso.

Palabras clave: Enseñanza remota; Experimentos; Materiales alternativos; Química.

\section{ISINTRODUÇÃO}

Diante do momento de pandemia vivenciado em todo o mundo com o surgimento do novo Coronavírus (SARS-CoV-2), a necessidade de adaptações no ensino colocou o tema da Educação em destaque, mais precisamente, o ensino remoto. Isto porque com a impossibilidade de aulas presenciais o Ministério da Educação emitiu a portaria 544 de 2020 autorizando o uso de recursos educacionais digitais e Tecnologias Digitais de Informação e Comunicação para o ensino de forma remota (VALENTE, et al. 2020).

Por outro lado, sabe-se que as atividades experimentais no ensino de ciências são de extrema importância para o desenvolvimento científico dos alunos. A aprendizagem é mais bem construída a partir da investigação, problematização e contextualização que a experimentação pode proporcionar (GUIMARÃES, 2009). Costa e Batista (2017) afirmam que a aprendizagem é mais efetiva quando se trabalha teoria e prática em conjunto, visto que as atividades práticas despertam a criatividade, desenvolvem o senso crítico dos alunos e os 
fazem refletir. Da mesma forma, Pires (2019) relata que a realização da experimentação no ensino de ciências faz com que o aluno passe a argumentar e a apropriar-se de conceitos.

De acordo com Leão e Alves:

Para que o ensino de ciências naturais possa contribuir na formação integral dos estudantes, é preciso que os professores desenvolvam propostas pedagógicas experimentais que possibilitem aos estudantes observar, analisar, investigar e apresentar soluções frente a esses eventos educativos experimentais. Dessa maneira, o estudo e a compreensão das ciências naturais poderão capacitar os estudantes a enfrentar outros problemas que surgirem levando-os a proporem soluções (LEÃO; ALVES, 2018).

A partir deste impasse, isto é, ensino remoto versus necessidade de aulas práticas verifica-se a importância da criação de metodologias alternativas para incorporar a experimentação no ensino remoto. Felizmente, os conceitos de Ciências e mais especificamente de Química são facilmente encontrados no cotidiano e deste modo, permitem a criação de diversos experimentos com materiais de baixo custo, que podem ou não serem realizados no ambiente do laboratório convencional. A construção de experimentos pelos estudantes não requer instrumentos elaborados ou de alto valor, na verdade, o ato da manipulação dos materiais, construção, observação e análise do fenômeno é que proporcionarão o bom desempenho do aluno em seu aprendizado (SILVA, et al. 2017).

É importante destacar também que apesar da prática experimental ser de elevada importância no processo de ensino e aprendizagem de Ciências, muitas escolas não possuem estrutura de laboratório para tal, ou possuem, porém, os docentes apresentam dificuldades no desenvolvimento destas atividades. Este fato pode ser atribuído à falta de experimentação durante a formação destes profissionais nos cursos de licenciatura (BARBIERI, 1993). Deste modo, é de suma importância que os estudantes passem por essa experiência, especialmente os alunos do curso de Licenciatura em Ciências, visto que os mesmos serão os futuros professores a atuarem na área de Ciências, e, portanto, devem estar preparados para propor a construção do conhecimento utilizando o ensino prático como aliado.

Diniz e Rodrigues afirmam que:

[...] se faz imprescindível gerar espaços de formação pedagogicamente diferenciados e inovadores, que valorizem as investigações por parte dos professores em sua práxis cotidiana, a fim de criar uma formação com consequente perfil docente de alto nível que atenda aos diversos pré-requisitos que se impõem a esse segmento de profissionais e que garanta uma formação de alta qualidade e envergadura diante das 
crescentes demandas oriundas da sociedade do conhecimento (DINIZ e RODRIGUES, 2020).

Com base nessa problemática, este trabalho descreve alguns experimentos propostos aos alunos do curso de Licenciatura em Ciências da Natureza da disciplina de Química Geral da Universidade Federal do Vale do São Francisco. De acordo com o plano pedagógico do referido curso observa-se que:

O curso de Licenciatura em Ciências da Natureza tem como objetivo formar profissionais aptos a atuarem na Educação Básica de forma investigativa e interdisciplinar, desenvolvendo atividades experimentais, aulas de campo, atividade de pesquisa e supervisionar Museus e Centros de Ciências. Através de uma abordagem integrativa das diversas áreas das Ciências, o Curso visa formar professores suficientemente preparados para compreender a realidade social onde está inserida a escola em que pretende atuar, adaptando a sua atuação diante das diferentes realidades encontradas e das rápidas transformações na sociedade (PPC do Curso de Licenciatura em Ciências da Natureza, UNIVASF, 2017).

Por outro lado, a disciplina de Química Geral II trabalhada de forma remota possui em seu plano de disciplina o objetivo geral de possibilitar ao aluno a compreensão de funções, propriedades e processos químicos reacionais, além de desenvolver o interesse científico motivando o aprendizado dos alunos através de atividades teóricas e experimentais correlacionadas ao seu cotidiano e a experimentos desenvolvidos pelos próprios alunos utilizando materiais domésticos.

Desse modo, para atingir a proposta do curso, bem como da disciplina, aulas teóricas e experimentos foram feitos de forma remota. Os alunos demonstraram empenho, satisfação e um ótimo aproveitamento na realização das aulas. Além disso, os estudantes do curso de Ciências também puderam colocar em prática o uso de materiais alternativos na construção dos experimentos, e assim, poderão levar este conhecimento adiante quando estiverem em sala de aula, rompendo barreiras como falta de laboratórios estruturados nas escolas, ou ainda, possíveis falhas em sua formação que os limitem na realização destas atividades.

\section{METODOLOGIA}

A proposta para realização da disciplina teórica e experimental de Química com os alunos da Graduação em Licenciatura em Ciências da Natureza da Universidade Federal do Vale do São Francisco consistiu em relacionar os conteúdos teóricos trabalhados com experimentos construídos pelos discentes de forma remota, empregando material de fácil acesso para o desenvolvimento das práticas propostas sob a orientação do professor. A 
comunicação do docente com os alunos ocorreu por meio de aulas síncronas e também através da orientação por vídeos gravados. Dúvidas ou informações solicitadas pelos alunos foram prontamente atendidas também através de e-mails e mídias sociais. Por outro lado, o desenvolvimento dos diversos experimentos pelos estudantes foram gravados e posteriormente, enviados para o professor por meio de links do You Tube. Nesses vídeos, os alunos foram orientados a mostrar o passo a passo da construção de cada um dos experimentos realizados, bem como, apresentar a explicação dos fenômenos observados relacionando-os com o conteúdo teórico estudado. Em momento posterior ao recebimento dos vídeos pelo professor, durante aula síncrona os vídeos foram apresentados e discutidos pela turma, permitindo a avaliação das dificuldades encontradas, bem como, o compartilhamento de adaptações realizadas. A sequência didática empregada é mostrada no fluxograma da Figura 1.

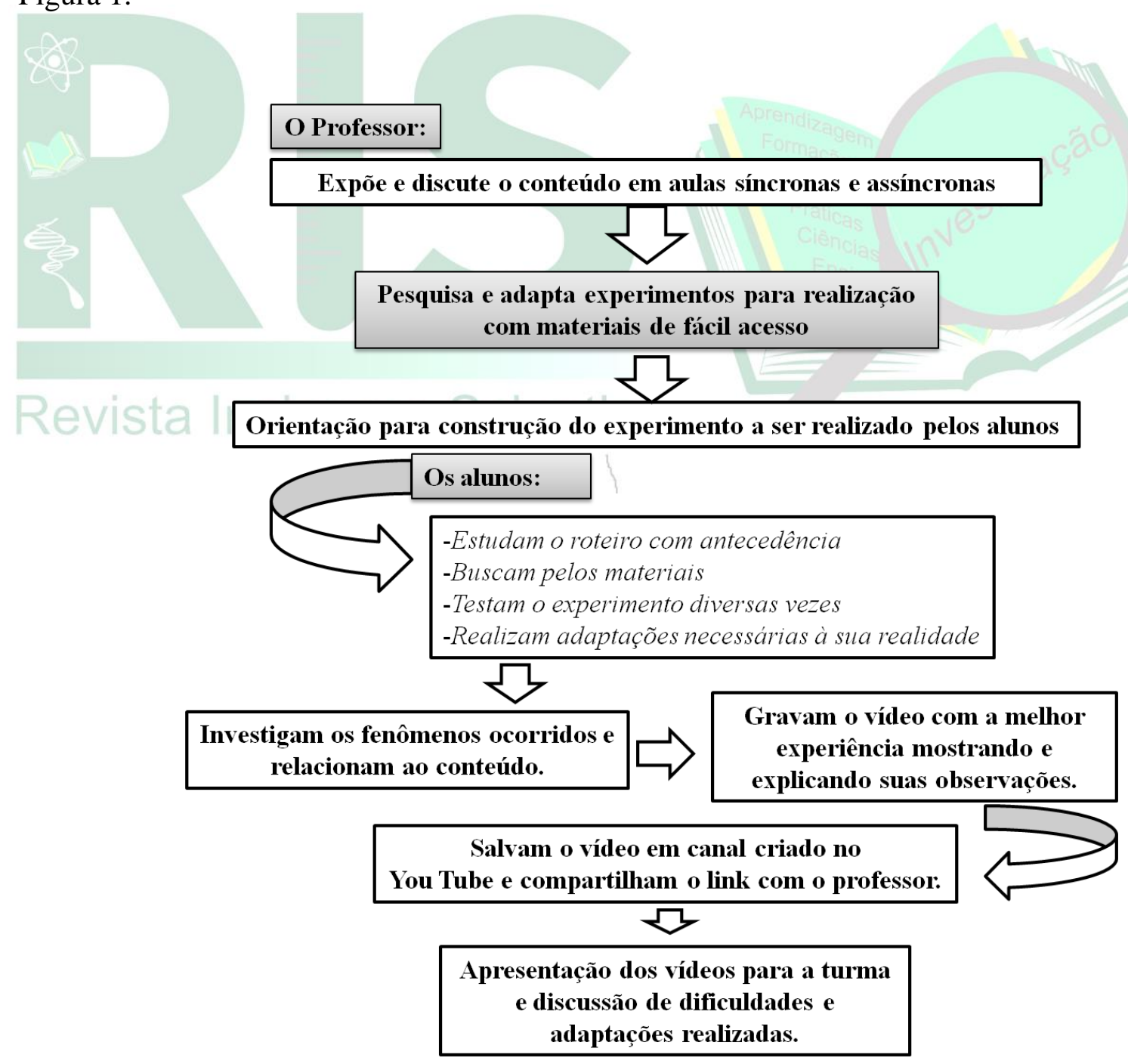


Figura 1- Fluxograma referente à sequência didática utilizada na realização de experimentos no ensino remoto de Química.

Fonte: Autoria própria.

O presente trabalho relata a vivência do ensino remoto da disciplina de Química Geral II, deste modo, são apresentados na Tabela 1 alguns dos temas trabalhados e os respectivos experimentos propostos e desenvolvidos pelos alunos de forma individual e em suas residências. Na sequência, também estão descritos os materiais empregados e o roteiro experimental de cada prática realizada.

Tabela 1 - Relação entre conteúdos de Química teóricos e experimentos realizados de forma remota por alunos da graduação do Curso de Licenciatura em Ciências da Natureza.

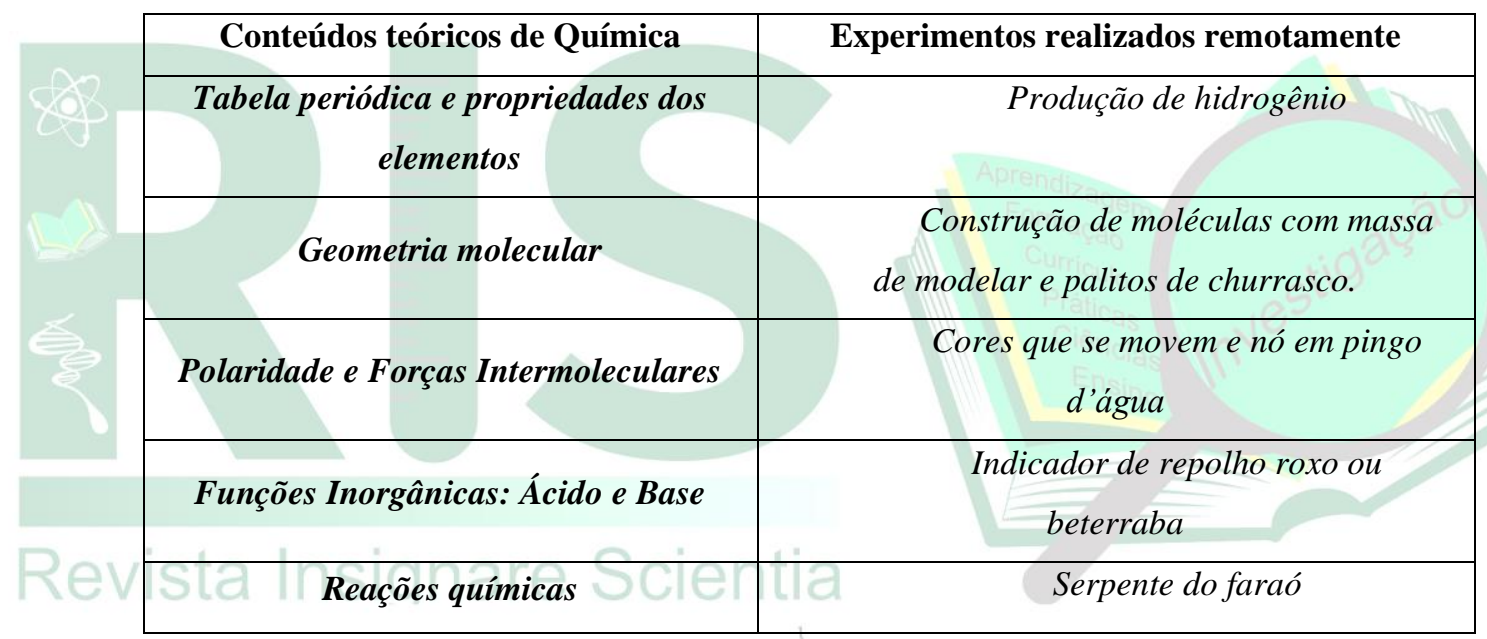

Fonte: Autoria própria.

\section{Experimento 1- Produção de Hidrogênio}

Materiais utilizados: • Soda cáustica $(\mathrm{NaOH})$ - Garrafa de vidro/garrafa pet • Fósforo • Funil • Latinha de refrigerante ou papel alumínio • Bexiga • Tesoura

Procedimento experimental: Coleta de gás hidrogênio na bexiga - Com a ajuda de um funil deve-se adicionar por volta de 4 colheres (sopa) de soda cáustica dentro de uma garrafa de vidro e na sequência, acrescenta-se de 300 a $500 \mathrm{~mL}$ de água na mesma. Deve-se agitar com cuidado a mistura para a solubilização da soda cáustica $(\mathrm{NaOH})$, atentando-se ao fato de que este processo libera calor e portanto, a garrafa deverá aquecer. Na sequência, tiras de uma latinha de refrigerante (alumínio) previamente cortada com a ajuda de uma tesoura deverão 
ser adicionadas dentro da mistura contida na garrafa e logo em seguida, encaixa-se uma bexiga na boca da garrafa para a coleta do gás que será sintetizado.

Obtenção de um "isqueiro" de gás hidrogênio - Dentro de uma garrafa PET de $500 \mathrm{~mL}$ deve-se adicionar 1 a 2 colheres (sopa) de soda cáustica com a ajuda de um funil. Na sequência, adiciona-se 100 a $200 \mathrm{~mL}$ de água dentro da garrafa. Agita-se para solubilização. Posteriormente, diversas bolinhas de papel alumínio preparadas previamente devem ser adicionadas na solução de soda cáustica. Após isso, fecha-se a garrafa com uma tampa que deverá conter um pequeno furo. Ao observar o início da reação com a mudança de cor e formação de bolhas, pode-se utilizar uma chama para "acender" o isqueiro. Isso pode ser feito aproximando a chama do furo feito na tampa da garrafa, por onde deverá estar saindo o gás hidrogênio formado.

\section{Experimento 2- Construção de moléculas com massa de modelar e palitos}

Materiais utilizados: • Massa de modelar, Bolas de isopor ou bexigas • Tintas guache - Palitos

Procedimento experimental: Construção de moléculas - Para a moldagem de diversas bolinhas capazes de representar os átomos, utilizam-se massinhas de modelar com cores variadas. Na sequência, pequenas quantidades de massinha são colocadas nas mãos para que se possam obter formas esféricas de diferentes tamanhos, posteriormente, palitos devem ser utilizados para conectar os átomos de forma similar às ligações químicas. É importante ligar os átomos respeitando os ângulos de ligação, bem como, a presença de possíveis pares isolados na molécula. A representação de pares isolados pode ser feita utilizando recorte de papel em forma de nuvem eletrônica ou orbital.

É também possível realizar a mesma prática empregando bolinhas de isopor e tinta guache de diferentes cores, substituindo a massinha de modelar. A utilização de bexigas é outra forma prática e muito exitosa para representação da geometria de moléculas. Neste caso, as moléculas são construídas apenas amarrando as bexigas de forma correspondente ao número de átomos da molécula que se deseja representar.

\section{Experimento 3- Cores que se movem e nó em pingo d'água}

\section{Materiais utilizados: • Leite - Corantes alimentícios - Detergente - Prato • \\ Garrafa PET • Água • Tesoura ou Objeto pontiagudo}


Procedimento experimental: Cores que se movem - Inicialmente adicionam-se 50 a $100 \mathrm{~mL}$ de leite em um prato e na sequência, goteja-se corante alimentício de diferentes cores sobre o leite, mantendo-o em repouso. Posteriormente, uma gota de detergente deve ser adicionada no meio do leite e então, observa-se o ocorrido. Gotas de detergente podem ser adicionadas em outras partes do leite para visualização do efeito.

Nó em pingo d'água - Para este experimento deve-se encher uma garrafa PET de $2 \mathrm{~L}$ com água e na sequência, acrescenta-se um corante alimentício para dar coloração a água. Em seguida, utiliza-se um objeto pontiagudo para fazer dois pequenos furos na garrafa (fechada com a tampa) com uma distância média de dois milímetros um do outro. Logo após, deve-se retirar a tampa da garrafa e observar a água sair pelos furos. Para dar o nó na água, utilizam-se os dedos polegar e indicador para unir os dois fluxos de água em um só, formando-se o "nó".

\section{Experimento 4- Indicador de repolho roxo ou beterraba}

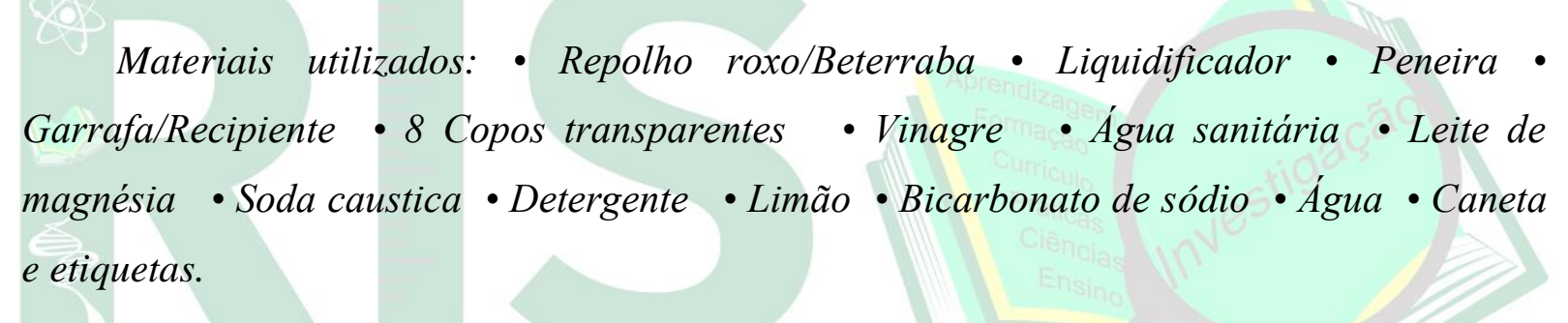

Procedimento experimental: Indicador ácido/base de repolho roxo - Primeiramente deve-se preparar o suco do repolho roxo (ou beterraba). Adiciona-se cerca de 1/3 de um repolho roxo em um liquidificador com 300 a $500 \mathrm{~mL}$ de água. Após triturar o repolho por alguns instantes, filtra-se a mistura utilizando-se um coador ou peneira. O filtrado deverá ser adicionado em uma garrafa ou recipiente.

Testando a acidez e basicidade - Deve-se colocar por volta de 1/3 do volume do copo de cada substância a ser testada em copos transparentes devidamente identificados com etiquetas. No caso das substâncias sólidas, é possível diluir uma pequena quantidade em água. Em seguida, adiciona-se em cada um dos copos contendo diferentes substâncias, uma pequena quantidade do filtrado do repolho, observando-se as cores formadas.

\section{Experimento 5- Serpente do Faraó}

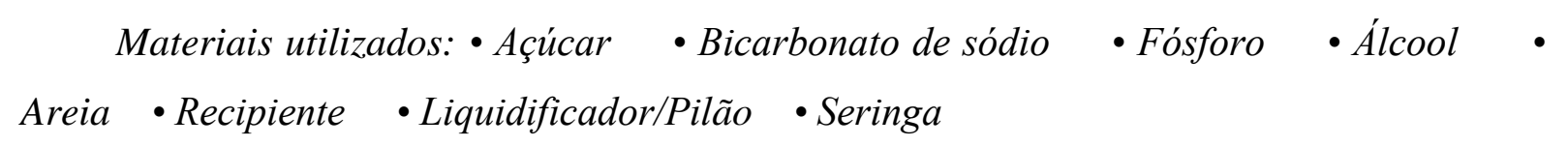

Recebido em: 08/03/2021

Aceite em: $11 / 07 / 2021$ 
Procedimento experimental: Serpente do Faraó - Inicialmente misturam-se duas colheres (sopa) de açúcar com uma colher (sopa) de bicarbonato de sódio. Esta mistura pode ser realizada utilizando um pilão grande (usado para amassar alho) ou pode-se adicionar a um liquidificador por alguns instantes. Em seguida, utilizam-se pequenas quantidades de álcool para dar certa liga à mistura. Coloca-se parte do material obtido dentro de uma seringa cuja ponta deve ter sido previamente cortada. Após compactar bem o material dentro da seringa, deve-se empurrar o embolo para se retirar a mistura na forma de um pequeno cilindro. É importante que a retirada do material seja feita diretamente dentro de uma pequena cavidade feita em um recipiente contendo areia. Na sequência, utiliza-se álcool (cerca de 20 a $30 \mathrm{~mL}$ ) para umedecer a areia e então, com muito cuidado, leva-se a chama de um fósforo para colocar fogo no sistema montado. Deve-se aguardar a queima para que se observe o crescimento da serpente.

\section{RESULTADOS E DISCUSSÕES}

A disciplina de Química Geral II na modalidade de ensino remoto se mostrou bastante exitosa. A maior parte do sucesso da disciplina pode ser atribuída à dinâmica empregada na mesma, com o desenvolvimento de pesquisa, investigação e construção de diversos experimentos com materiais domésticos.

De acordo com Guimarães (2009) a realização de experimentos trata-se de uma forma eficaz de ensino, desde que o aluno seja estimulado a investigar, problematizar e contextualizar as questões envolvidas no tema, deste modo, o aluno passa a ter uma ação ativa no processo. Diante disso, é possível constatar que a proposta de experimentos de forma remota apresentou-se ainda mais interessante, visto que os alunos produziram e adaptaram as práticas em suas casas, e por isso, foi inevitável que estes realizassem pesquisa e investigação para entender todo o processo e atingir o objetivo almejado. Alguns dos conteúdos trabalhados e experimentos realizados de forma remota são apresentados na sequencia por meio de fotos enviadas pelos alunos.

Na Figura 2 são mostrados os resultados referentes à primeira proposta de experimento, onde se observa uma prática simples referente à síntese de gás hidrogênio. Os temas Tabela Periódica, Propriedades dos Elementos e Reação Química foram discutidos. Nesta prática, a 
mistura entre o alumínio $(\mathrm{Al})$ da latinha com a solução de soda cáustica $(\mathrm{NaOH})$ em água provoca a ocorrência de uma reação química, de acordo com a Equação 1.

$$
2 \mathrm{NaOH}+2 \mathrm{Al}+2 \mathrm{H}_{2} \mathrm{O} \rightarrow 2 \mathrm{NaAlO}_{2}+3 \mathbf{H}_{2}
$$

Ao falar sobre a Tabela Periódica é possível que se destaque um elemento químico para que sejam observadas algumas das suas propriedades de forma experimental. Deste modo, a reação química em questão (Equação 1) permite que se faça de uma maneira simples a produção do elemento químico hidrogênio na forma gasosa. Como apresentado na Figura 2-a e 2-b, o gás obtido pode ser facilmente coletado em uma bexiga. Devido sua propriedade de baixa densidade, sendo esta inferior ao ar, à bexiga com o gás hidrogênio flutua e tende a subir para o alto se estiver livre. A elevada inflamabilidade do gás também pode ser verificada quando se aproxima uma chama do orifício da garrafa onde ocorre a reação e a liberação do gás, como visto nas Figuras 2-c e 2-d. Destacam-se também os diversos fatores que indicam a ocorrência de um fenômeno químico, pois quando o alumínio entra em contato com a solução de soda cáustica que é transparente, o recipiente aquece devido à liberação de calor pela reação, além disso, pequenas bolhas de gás são formadas no meio e a cor da mistura dentro da garrafa torna-se cinza (SANTOS; SILVA, 2015).
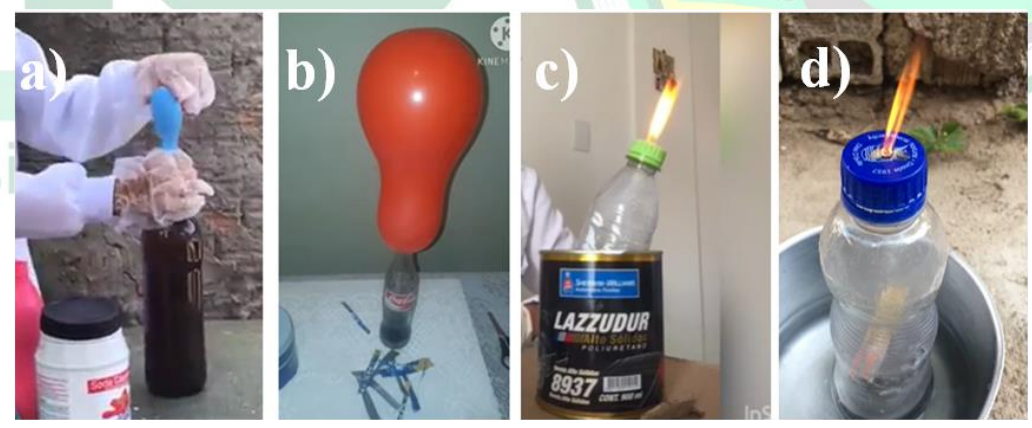

Figura 2- Experimentos de produção de hidrogênio: a) e b) Coleta de gás hidrogênio na bexiga; c) e d) Isqueiro de gás hidrogênio.

Fonte: Autoria própria.

Para tratar do conteúdo de Geometria Molecular é imprescindível que os alunos possam visualizar de perto as moléculas e seus diferentes arranjos espaciais. Assim, a proposta de experimento remoto consistiu na construção de moléculas de diferentes substâncias e com a apresentação de geometrias como a linear, angular, trigonal plana, tetraédrica, bipiramidal entre outras. Como observado na Figura 3, os alunos desempenharam com excelência a tarefa 
dada e montaram moléculas empregando o material que tinham disponível, como massa de modelar, bolas de isopor ou bexigas. Neste ponto, os alunos puderam compreender a influencia da organização espacial dos átomos em uma molécula e de que modo isto interfere nas propriedades apresentadas pelas substancias, como por exemplo, polaridade, solubilidade, pontos de fusão e ebulição (MENEZES, et al. 2016).
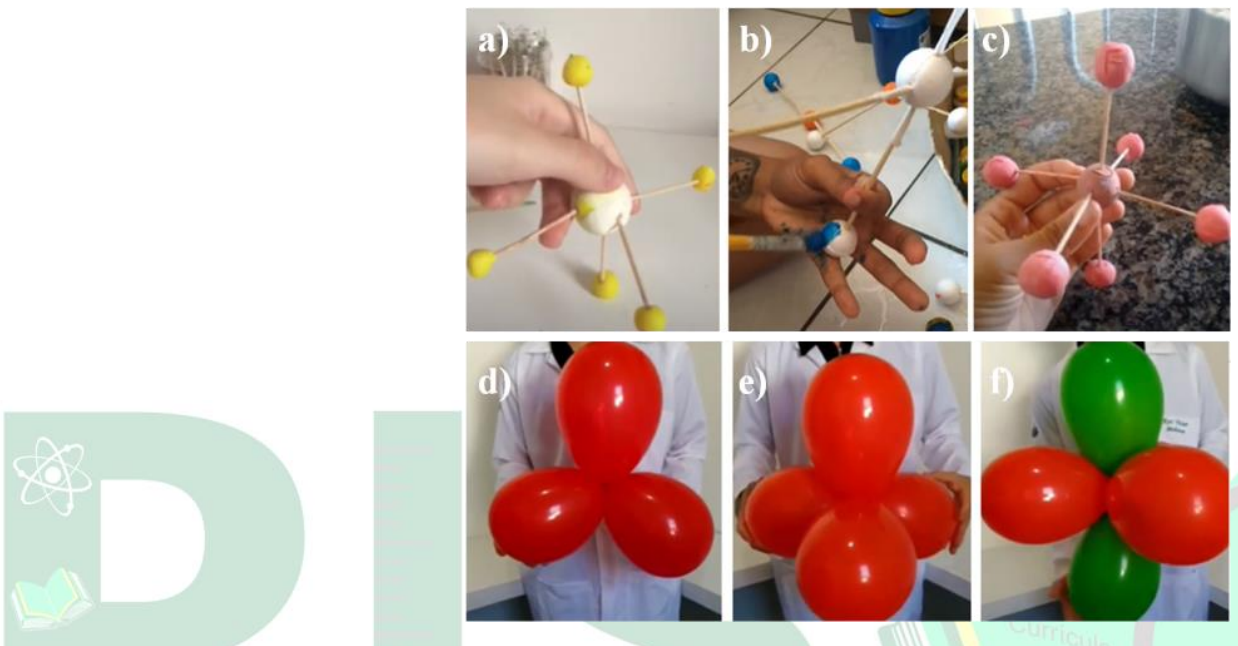

Figura 3- Prática de construção de moléculas com diferentes geometrias: a), b) e c) Moléculas feitas com bolinhas de massinha ou isopor; d), e) e f) Geometrias moleculares com bexigas.

Fonte: Autoria própria.

Para trabalhar o conteúdo sobre Polaridade e Forças Intermoleculares, foram propostos experimentos utilizando-se o leite integral, considerando-se que este é formado por lipídios que são constituídos por moléculas apolares; corantes alimentícios que são substâncias polares e o detergente que é formado por uma longa cadeia carbônica apolar e hidrofóbica, porém, também possui em sua extremidade uma região polar e hidrofílica, isto é, trata-se de uma molécula anfipática (LEÃO; ALVES, 2018). Deste modo, ao adicionar-se gotas de corante no leite, estas não se misturam devido à falta de interação entre a substância apolar (leite) com a substância polar (corantes). Por outro lado, quando se coloca gotas de detergente sobre o sistema (leite + corantes), verifica-se que ocorre uma movimentação das substâncias e elas se misturam. Este efeito é atribuído à interação entre a parte apolar das moléculas do detergente com a gordura causando o rompimento da tensão superficial existente, e assim, o corante consegue interagir com a água e componentes polares presentes no leite, misturando-se e provocando o movimento das cores que se observa nas Figuras 4-a), 4-b) e 4-c) (LEÃO; ALVES, 2018). 
As forças intermoleculares também podem ser demonstradas experimentalmente realizando-se a prática nó em pingo d’água, apresentada nas Figuras 4-d), 4-e) e 4-f). Como é de conhecimento, as forças intermoleculares formadas por ligações de hidrogênio tratam-se de uma das mais fortes (ROCHA, 2001) e esta, está presente na água. Deste modo, as moléculas de água que são polares são atraídas entre si através das forças intermoleculares, por isso, quando os dois fluxos de água que estão próximos são unidos com um "nó" as moléculas interagem e formam um único fluxo. Ao interromper a aproximação das moléculas, a interação é quebrada e os dois fluxos se formam novamente.
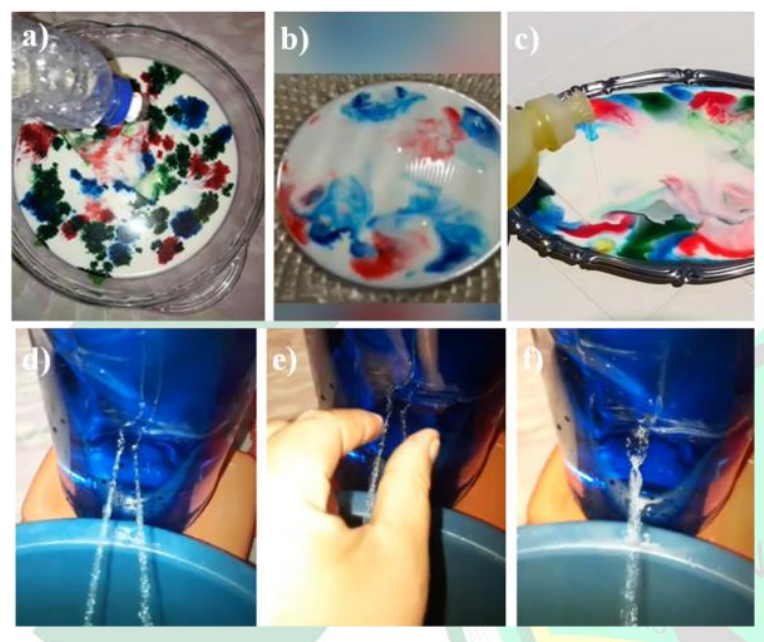

Figura 4- Experimento de polaridade e forças intermoleculares: a), b) e c) Cores que se movem; d), e) e f) Nó em pingo d'água.

Fonte: Autoria própria.

O conteúdo que trata das Funções Inorgânicas- ácidos e bases pode ser mais bem compreendido quando os alunos têm a possibilidade de observar estas substâncias em seu cotidiano. $\mathrm{O}$ experimento utilizando o repolho roxo ou beterraba como indicador ácido e base consiste de uma excelente opção para o desenvolvimento da atividade de forma remota. Nesta prática, emprega-se o extrato do repolho roxo devido à presença de substâncias denominadas de antocianinas, estas modificam sua estrutura em função do $\mathrm{pH}$ do meio em que se encontram. A alteração estrutural ocorre quando o íon hidrogênio (ácido) é adicionado ou removido da molécula, o que provoca mudança em sua coloração, e assim, é possível utilizála como indicador da acidez ou basicidade do meio em que é colocada. É importante destacar que as antocianinas podem ser encontradas em diversas fontes, como beterraba, jabuticaba, uva e pétalas de flores (TERCI; ROSSI, 2002), portanto, o indicador natural apresenta-se como um material de fácil acesso. Ao realizarem o experimento com um extrato contendo 
antocianina, os alunos puderam observar diversas cores que variam em função do $\mathrm{pH}$ das substâncias testadas, como por exemplo, vermelho para ácidos, violeta em meio neutro e amarelo para bases. Na Figura 5 são apresentados os resultados de experimentos de diferentes alunos. Nestes, pode-se observar que diversas substâncias de uso cotidiano foram testadas por eles. Também é possível visualizar uma grande variedade de cores que são atribuídas aos diferentes pHs dos materiais.
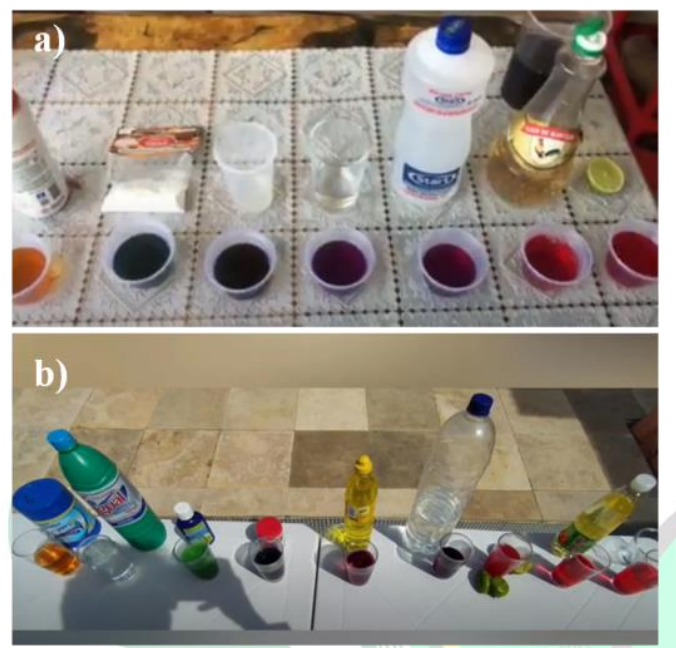

Figura 5- Prática sobre indicador natural ácido e base: a) e b) Testes realizados por diferentes alunos.

Fonte: Autoria própria.

Para falar sobre Reações Químicas diversas possibilidades de experimentos podem ser realizados, no entanto, o apelo visual da prática a ser feita dentro dessa temática é extremamente importante. Além disso, deve-se considerar também a facilidade de materiais a serem empregados, visto que os mesmos foram produzidos pelos alunos em suas residências. Diante disso, a reação química conhecida como serpente do faraó foi escolhida para o estudo do tema. Nesta prática utilizou-se a sacarose $\left(\mathrm{C}_{12} \mathrm{H}_{22} \mathrm{O}_{11}\right)$ comumente conhecida como açúcar e o hidrogenocarbonato de sódio $\left(\mathrm{NaHCO}_{3}\right)$ ou simplesmente, bicarbonato de sódio. Quando as substâncias envolvidas no processo queimam, as reações de combustão e decomposição ocorrem gerando novas substâncias como hidrogênio, oxigênio, carbono e água. A formação destas causa um grande efeito visual que facilita a constatação do fenômeno químico. As reações envolvidas são apresentadas nas Equações 2-5.

A queima do açúcar caracteriza-se como uma combustão completa (Equação 2) e incompleta (Equação 3) que resulta na formação de substâncias como carbono, gás carbônico e água: 


$$
\begin{aligned}
& \mathrm{C}_{12} \mathrm{H}_{22} \mathrm{O}_{11(\mathrm{~s})}+12 \mathrm{O}_{2(\mathrm{~g})} \rightarrow 12 \mathbf{C O}_{2(\mathrm{~g})}+11 \mathrm{H}_{2} \mathrm{O}_{(\mathrm{l})} \\
& \mathrm{C}_{12} \mathrm{H}_{22} \mathrm{O}_{11(\mathrm{~s})} \rightarrow 12 \mathrm{C}_{(\mathrm{s})}+11 \mathrm{H}_{2} \mathrm{O}_{(\mathrm{l})}
\end{aligned}
$$

O bicarbonato de decompõe em carbonato de sódio, gás carbônico e água, Equação 4:

$$
2 \mathrm{NaHCO}_{3(\mathrm{~s})}{ }^{\text {calor }} \rightarrow \mathrm{Na}_{2} \mathrm{CO}_{3(\mathrm{~s})}+\mathrm{CO}_{2}(\mathrm{~g})+\mathrm{H}_{2} \mathrm{O}_{(\mathrm{l})}
$$

O carbonato de sódio formado na Equação 4 se decompõe em óxido de sódio e mais gás carbônico, Equação 5:

$$
\mathrm{Na}_{2} \mathrm{CO}_{3}(\mathrm{~s}) \stackrel{\text { calor }}{\rightarrow} \mathrm{Na}_{2} \mathrm{O}_{(\mathrm{s})}+\mathrm{CO}_{2}(\mathrm{~g})
$$

A formação da "serpente" observada nos experimentos mostrados na Figura 6, ocorre devido ao carbono gerado na combustão incompleta do açúcar (Equação 3) e aos produtos gasosos verificados nas Equações 2, 4 e 5. Todo o gás presente causa a expansão do carbono que o faz crescer e o torna uma estrutura porosa (ULLMANN, et al. 2014).
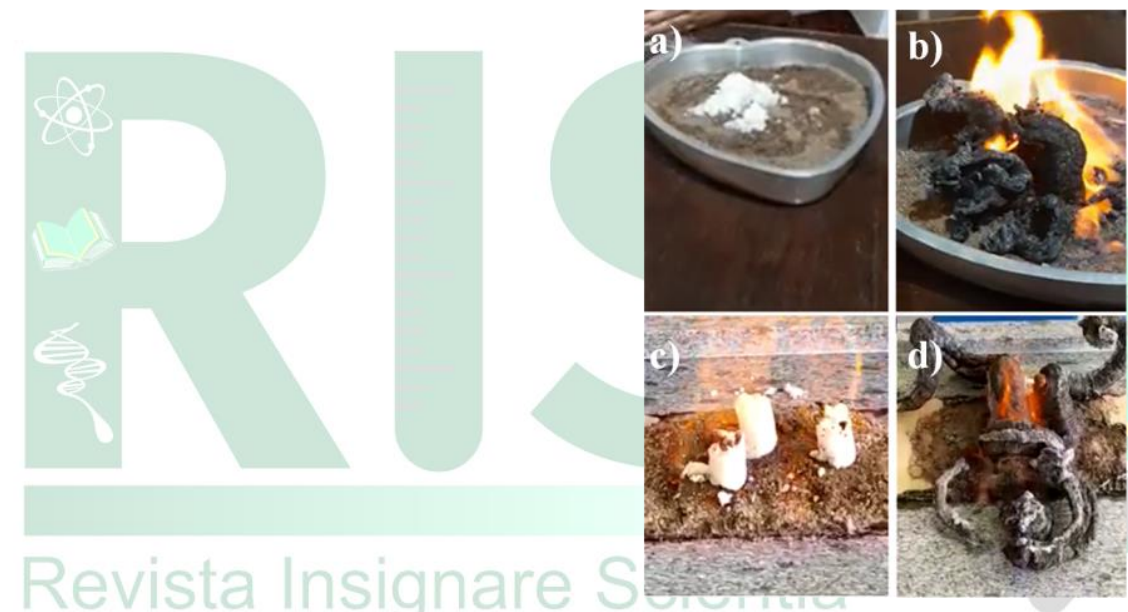

Figura 6- Experimento sobre reações químicas: Testes realizados por diferentes alunos. a) e c) Procedimento inicial da reação; b) e d) Resultados obtidos para a formação da serpente do faraó.

Fonte: Autoria própria.

\section{CONSIDERAÇÕES FINAIS}

Apesar do desafio de ministrar um curso de forma remota, principalmente sendo este um curso para alunos Licenciandos em Ciências e tratando-se de uma disciplina que tem a característica experimental tão forte como a Química, é possível afirmar que houve sucesso em sua condução, principalmente com relação às atividades práticas. Esta afirmação é atribuída ao retorno dado pelos alunos no decorrer da disciplina, os quais realizaram todas as práticas recomendadas e demonstraram um bom entendimento dos conteúdos ao final do curso. Destaca-se também que durante as discussões em momento síncrono sobre os experimentos realizados, alguns poucos alunos relataram dificuldade para encontrar um ou 
outro item necessário para a construção da prática, porém, estes utilizaram de pesquisas para adaptações, e desse modo, enriqueceram ainda mais a aula proposta. Relatos destes alunos quanto à disciplina foram coletados a partir de um formulário Google para uma autoavaliação da mesma. Os formulários foram respondidos sem necessidade de identificação. Na sequência são apresentados alguns destes:

Aluno X- "Foram trabalhosos, no entanto, foi uma experiência incrivel, pois através dos experimentos adquiri conhecimentos que somente na prática seria possível compreender".

Aluno Y- "Possibilitou bastante o aprendizado, facilitou de entendermos o assunto e foi divertido".

Aluno Z - "Os experimentos foram melhores que no laboratório onde são tediosos e trabalhosos, eu achei melhor na questão da aprendizagem esse modelo (experimentos simples e feitos por qualquer pessoa, sem precisar do laboratório)".

Após avaliar todo o processo e observar a satisfação dos alunos ao realizarem as práticas, entende-se que a experiência vivenciada na situação de ensino remoto apresenta-se com potencial para que seja compartilhada, pois possibilitou não só a prática experimental remota, como também, o incentivo a utilização de materiais cotidianos e de fácil acesso no ensino de Química.

\section{REFERÊNCIAS}

BARBIERI, M. R. Projeto USP/BID - Formação de professores de ciências. in: Boletim da Filosofia, n.6, p.4, 1993.

COSTA, G. R., BATISTA, K. M. A importância das atividades práticas nas aulas de ciências nas turmas do ensino fundamental. $\boldsymbol{R E} \boldsymbol{V} \boldsymbol{A S \boldsymbol { F }}$, v. 7, n. 12, p. 06-20, 2017.

DINIZ, M. I. G., RODRIGUES, L. A. A pesquisa como princípio pedagógico: Os desafios na práxis docente para ressignificação de conhecimentos. Revista Insignare Scientia, v. 3, n.3. 2020.

GUIMARÃES, C. C. Experimentação no Ensino de Química : Caminhos e Descaminhos Rumo à Aprendizagem Significativa. Quím. Nova na Escola, v. 31, n.3, 2009. 
LEÃO, M. F., ALVES, A. C. T. Oficina pedagógica na licenciatura em química com experimentos e materiais alternativos para o ensino fundamental. Revista REAMEC, v. 6, n. $1,2018$.

MENEZES, F. L., SILVA, S. F., MENEZES, S. C., SILVA, D. S. O Ensino de geometria molecular com materiais de baixo custo. Conex. Ci. e Tecnol. v. 10, n. 4, p. 101 - 107, 2016.

PIRES, C. R., Mostra de ciências como uma forma de aprendizagem a partir da experimentação. Revista Insignare Scientia, v. 2, n.3- Edição Especial: Ciclos Formativos em Ensino de Ciências. 2020.

PPC - Projeto pedagógico do curso de Licenciatura em Ciências da Natureza. Colegiado de Licenciatura em Ciências da Natureza, Campus Senhor do Bonfim-Ba. Universidade Federal do Vale do São Francisco - Univasf, 2017.

ROCHA, W. R. Interações Intermoleculares. Cadernos Temáticos de Química Nova na Escola Interações. n.4, 2001.

SANTOS, D. O., SILVA, G. S. Produção de hidrogênio a partir de materiais alternativos por alunos do Ensino Médio. Sc. Plena, v. 11, n.6, 2015.

SILVA, J. N., AMORIM, J. S., MONTEIRO, L. P., FREITAS, K. H. G. Experimentos de baixo custo aplicados ao ensino de química : contribuição ao processo ensino-aprendizagem . Sc. Plena, v. 13, n.1, 2017.

TERCI, D. B. L., ROSSI, A. V. Indicadores naturais de pH: Usar papel ou solução?. Quím. Nova, v. 25, n. 4, p. 684-688, 2020.

ULLMANN, M. A., WALLAU, W. M., BIANCHINI, D., SCHNEID, A. C., MONTENEGRO, L. M. P. "Serpentes de Faraó" - A história de uma brincadeira pirotécnica e sua aplicabilidade no ensino de princípios químicos básicos. Quím. Nova, v. 37, n. 7, p. 12361243, 2014.

VALENTE, G. S. C., MORAES, E. B., SANCHEZ, M. C. O., SOUZA, D. F., PACHECO, M. C. M. D. O ensino remoto frente às exigências do contexto de pandemia: Reflexões sobre a prática docente. Research, Society and Development, v. 9, n. 9, 2020. 